\title{
Preparation and properties of iron-boron metallic glass ribbons melt spun in air
}

\author{
D C AGRAWAL and E A CHAKACHERY \\ Advanced Centre for Materials Science, Indian Institute of Technology, Kanpur 208016 , \\ India \\ MS received 22 October 1984; revised 4 February 1985
}

\begin{abstract}
The preparation of metallic glass ribbons by melt spinning is a simple technique; however, a researcher often faces many problems when undertaking the preparation of such ribbons. The difficulties encountered are oxidation of the melt, choking of the nozzle by the solidified metal, formation of metal globules or ribbon fragments, oxidation of the ribbons, etc. These problems are particularly severe when working with high melting point alloys. This report describes certain experimental techniques used to overcome problems in preparation of metallic glass ribbons of iron-boron and other high melting point alloys. The ribbons thus produced have been characterized by transmission electron microscopy, mechanical tests and differential thermal analysis. The mechanical strength of the ribbon is comparable to the best recorded strength for ribbons of similar composition. The DTA data support the view that the formation of the phase $\mathrm{Fe}_{2,3} \mathrm{~B}_{6}$ takes place upon crystallization of the eutectic alloy.
\end{abstract}

Keywords. Metallic glass ribbons; melt spinning: iron-boron alloys.

\section{Introduction}

Considerable research effort is being devoted to the study of metallic glasses and microcrystalline alloys today because of their technological importance and interest to science. The preparation of samples of metallic glasses in the laboratory is, in principle, straightforward; however, many researchers appear to be using materials obtained from other sources rather than preparing their own--thereby losing some freedom in the selection of compositions (Parashar et al 1984: Bhanu Prasad et al 1984; Yousuf and Govinda Rajan 1984; Namboodhiri et al 1983). The comparative ease of preparing ribbons of materials with low melting points (e.g. aluminum alloys) as opposed to preparing ribbons of materials with high melting points partially explains this action of the researchers. Most of the technologically important metallic glasses and rapidly solidified microcrystalline materials belong to the group of high melting point alloys. Thus, more attention should be devoted to this group.

Some reports in scientific literature are helpful to the beginner attempting the fabrication of rapidly solidified ribbons (Pavuna 1981; Liebermann 1980; Budhani et al 1982); however, some aspects, particularly the problem of alloy oxidation during melt spinning in the air are not covered extensively.

The purpose of this report is to describe the characteristics of metallic glass ribbons and to share our experiences in the preparation of iron based metallic glass ribbons by melt spinning in air. It is hoped that this may help other researchers also to undertake similar efforts. This work has been reported in brief earlier (Chakachery and Agrawal 1982). 


\section{Experimental details}

A single roller melt spinning apparatus, shown schematically in figure 1 was used to prepare the metallic glass ribbons. In the melt spinning technique, a jet of molten material formed by ejecting the melt under pressure through an orifice is made to impinge on the surface of a rapidly moving substrate. Quenching of the melt puddle formed at the foot of the jet takes place at a rate of $10^{6}$ degrees $\mathrm{sec}^{-1}$ for metallic melts. A ribbon is formed and is thrown off the surface of the substrate by the centrifugal force. A view of the experimental set up is seen in figure 2.

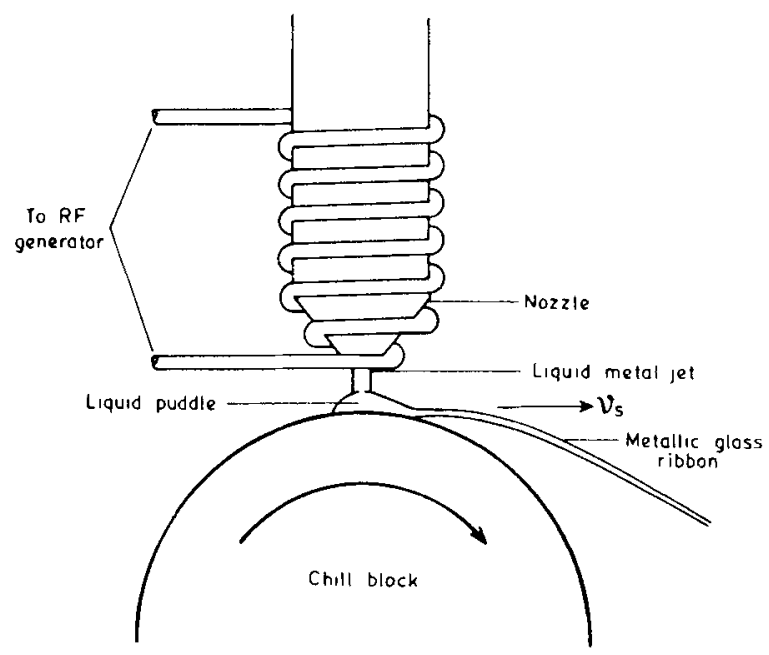

Figure 1. Schematic view of melt spinning apparatus.

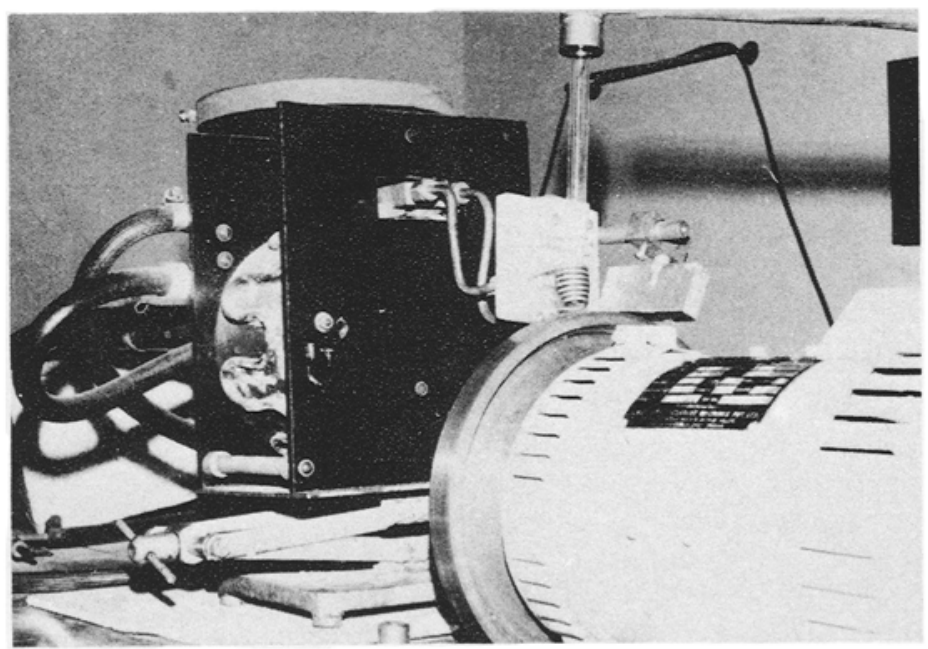

Figure 2. A view of the melt spinning apparatus set up in the laboratory. 


\subsection{The chill block}

Initially a disc $220 \mathrm{~mm}$ (dia) $\times 25 \mathrm{~mm}$ (thickness) cast from copper was used as the chill block. Although this performed satisfactorily, we occasionally faced some problems due to the presence of pinhole porosity in the cast disc. Thus, a rolled copper plate of similar diameter but about $20 \mathrm{~mm}$ thickness was used instead. The copper disc was directly mounted on to a $0.5 \mathrm{hp}$ motor (Elmot Direct Current Machines, Thana), whose speed could be continuously varied from 0 to $3000 \mathrm{rpm}$ using a thyristor-control (Ultraflex E Drive, Bhartia Cutler Hammer Ltd., New Delhi; alternatively, a simple circuit consisting of a diode rectifier with variable $A C$ voltage input from an autotransformer can be used for this purpose as the torque variations are low). Thus a surface speed of upto $34.5 \mathrm{~m} \mathrm{sec}^{-1}$ can be obtained. The diameter of the chill block and hence the maximum surface speed cannot be increased much further because deformation of the chill block may take place at high speeds (Srinath 1983). In our experiments, the wheel speed was $2800 \mathrm{rpm}$, giving a linear speed of $32.5 \mathrm{~m} \mathrm{sec}^{-1}$.

\subsection{The RF generator}

The RF generator used was a $3 \mathrm{~kW}, 450 \mathrm{kHz}$ model (Pal Industries, Ghaziabad). A custom-made transformer was connected to the output coil of the generator to provide a high current, low voltage output. This was necessary in order to melt small quantities $\left(1\right.$ to $4 \mathrm{~g}$ ) of high melting point (up to $1500^{\circ} \mathrm{C}$ ) alloys. The power to the $\mathrm{RF}$ coil could be continuously varied by varying the input power to the generator.

\subsection{The RF coil}

The design of the RF coil is also important. The factors to be considered are (a) diameter of the copper tube used to construct the coil (b) number of coil turns per unit length (c) empty space between adjacent turns of the coil (d) total number of turns in the coil and (e) gap between the coil and the fused silica or ceramic tube containing the alloy to be melted. Factors (a) and (c) are interrelated. The maximum number of turns wound per unit length with an absolute minimum of gap between adjacent turns was found to be necessary in order to derive the maximum power from the rather limited capacity generator at our disposal. A $3 \mathrm{~mm}$ diameter copper tube used by the refrigeration industry is ideal as it allows a sufficient number of turns per unit length without unduly restricting the flow of cooling water. The coil should be wound with its internal diameter only 1 to $2 \mathrm{~mm}$ larger than the silica tube used for melting the alloy in order to effect maximum coupling between the coil and the alloy pieces. Also, the coil should be tapered to closely follow the tube where the latter is tapered into a nozzle. The maximum temperature that can be reached increases with the decreasing number of total turns in the coil. About six turns were found to be the maximum that could be used with our apparatus to heat iron based alloys to a sufficient superheat. The coil was wound on a lathe machine over a mild steel mandrel especially designed for this purpose.

\subsection{The melting and ejection nozzle}

The alloys were melted and ejected on the rotating wheel from a fused silica tube $12 \mathrm{~mm}$ (o.d.) and $10 \mathrm{~mm}$ (i.d.). The tube was tapered at one end to a nozzle with a hole varying 
between 0.5 and $2 \mathrm{~mm}$ dia. Usually it was found that with a hole diameter larger than $1 \mathrm{~mm}$, ejection of the melt took place before the ejection pressure could be applied, leading to poor process control. However, to get ribbons wider than $1 \mathrm{~mm}$, it may be necessary to have the nozzle hole diameter larger than $1 \mathrm{~mm}$. In that case, with some experience, it is frequently possible to apply the ejection pressure at the right moment before the melt ejects by itself.

The angle of the nozzle to the wheel surface was maintained at $90^{\circ}$. Although, this angle can be reduced, it results in a reduction in the width of the ribbon without providing any compensating advantage (Liebermann 1980).

The connections to the other end of the silica tube were so arranged that the tube could be connected to either a rotary vacuum pump (Precivac Engineering Co., Calcutta) or to a high purity argon gas cylinder (IOLAR 2, Indian Oxygen Ltd.). The argon gas was further purified by passing over copper turnings heated to $450^{\circ} \mathrm{C}$ to remove trace oxygen. This is necessary to guard against the possibility of oxidation of the melt.

\subsection{Materials}

The experiments described in this report have been carried out using a set of iron-boron alloys made with a commercial ferroboron (M/s Kromium and Chemicals, Kanpur). This alloy is used in steelmaking and its composition was determined to be $\mathrm{Fe}_{40} \mathrm{~B}_{52} \mathrm{Si}_{6} \mathrm{Mn}_{12} \mathrm{Co}_{066}$. This was chosen as a source of boron for its low cost, easy availability and also because the primary interest was in gaining experience in making iron based ribbons. Subsequently, a variety of pure metals and alloys have been made into ribbons and some results have been reported (Sridhar and Agrawal 1983).

99.9\% pure iron (Alpha Products, USA) was added to the commercial ferro-boron alloy, to attain the desired iron content. The alloys were prepared in an arc furnace under an argon atmosphere and remelted twice to homogenize the composition. The alloy buttons thus obtained were cut, using a saw (Microslice-2, Metals Research Ltd., Cambridge, UK), into pieces which can be fit into the fused silica tube. The pieces should, however, be as large as possible to promote rapid heating and avoid undue oxidation.

The chemical composition of the alloys was determined using an IL 751 Atomic Absorption Spectrophotometer (Instrumentation Laboratory, Lexington, USA). A total of five compositions given in table 1 were made into ribbons and studied.

Table 1. Compositions of alloys used to prepare ribbons (atom percent)

\begin{tabular}{cccccc}
\hline $\begin{array}{c}\text { Alloy } \\
\text { number }\end{array}$ & Fe & B & Si & Mn & C \\
\hline 1 & $83 \cdot 7$ & 14.6 & 1.9 & 0.4 & 0.2 \\
2 & $82 \cdot 0$ & 16.7 & 0.8 & 0.3 & 0.2 \\
3 & $80 \cdot 6$ & 17.9 & 0.9 & 0.4 & 0.2 \\
4 & 79.1 & 18.6 & 1.5 & 0.5 & 0.3 \\
5 & 79.6 & 19.9 & 0.3 & 0.1 & 0.1 \\
\hline
\end{tabular}




\section{Preparation of the ribbons}

Initial attempts to melt spin the ribbons resulted in globules of red hot metal flying all around the laboratory. At best, a highly oxidized, irregular piece of ribbon was occasionally obtained. With some experimentation and analysis, the conditions for the formation of continuous, bright ribbons of good quality were established. These conditions and details of the experimental techniques used are described below.

\subsection{Evacuation and flushing of the nozzle}

Pieces of the alloy to be cast into ribbons were placed in the fused silica nozzle such that they were entirely surrounded by the RF coil. As mentioned earlier, these pieces should be as large as possible. The nozzle hole was closed and the nozzle evacuated by the rotary pump. Purified argon gas was then allowed to flush the nozzle for a few minutes after which the evacuation and flushing cycle was repeated. This was done for a total of three times after which a very small flow of argon was maintained through the nozzle. Such a procedure minimized the chances of melt oxidation.

\subsection{Positioning the nozzle}

The gap between the nozzle tip and the chill block surface is critical. If it is too large, the molten alloy oxidizes or freezes before it reaches the chill block surface and this results in metal globules being produced. If the distance is too small, the nozzle tip may hit the wheel surface due to the inevitable vibrations when the latter is set into motion at a high speed. However, it is best to have as small a gap as possible, consistent with the latter requirement. A gap of about $1 \mathrm{~mm}$ was found to be satisfactory.

\subsection{Heating schedule}

The power input to the RF coil was rapidly raised (in about $30 \mathrm{sec}$ ) to a level just below that required to melt the alloy (as determined by previous experimentation) and held there for some time (one minute). The chill block had already been set in motion at the desired speed at this point as the air dragged with the wheel causes some cooling of the alloy: if the wheel is set in motion later, say, just before ejection, then this cooling may cause freezing of the melt in the nozzle during ejection. The holding of the alloy at just below the melting point was necessary in order to heat up the lower section of the nozzle through which the molten alloy will pass. If this lower section remained cold (or if it were too long) the alloy would freeze up in this section during attempts to eject it. After the heating up of the nozzle section was over, the heat input was increased by about $25^{\circ}{ }_{0}$ so that the alloy melted and quickly superheated to a sufficient degree. Although the actual temperature of the alloy was not measured, it was found that enough superheating was essential to compensate for the cooling of the alloy that would take place during its passage through the relatively cold nozzle and the air gap between the nozzle tip and the chill block. Ejection pressure was now applied by opening the gas valve completely. This pressure was preset at the gas cylinder at 0.5 to $1.0 \mathrm{~kg} \mathrm{~cm}^{-2}$. The final melting and ejection step was over in 5 to 10 seconds. 


\subsection{Dwell time on the substrate}

The precautions required to prevent the oxidation of the melt during the melt spinning operation have been described above. Even slight oxidation of the melt has significant effects on its viscosity and wetting characteristics and may result in an unsuccessful run. However, despite the above precautions, an oxidized ribbon may still be produced. This is due to the oxidation taking place after ribbon formation because of insufficient contact time of the ribbon with the substrate (Tenwick and Davies 1984). The ribbon is thrown off the substrate before it has cooled sufficiently and gets oxidized after leaving the substrate. The contact time depends on the properties of the metal being cast, the substrate material, the speed and the surface finish of the substrate. Thus steel substrates have been found to be superior to copper substrates for $\mathrm{Ni}$ based super alloys and for Fe-B-Si-amorphous alloys (Luborsky et al 1982). We found that imparting a matte finish to the substrate (e.g. polishing with a $4 / 0$ emery paper) and increasing the wheel speed so as to increase the quench rate suppressed the tendency towards ribbon oxidation.

When all the above precautions were taken, it was possible to routinely produce continuous ribbons 7 to 10 metres long, $1 \mathrm{~mm}$ wide and $30 \mu \mathrm{m}$ thick, having bright surfaces with no apparent oxidation. Figure 3 is a photograph of one such ribbon.

\section{Characteristics of the ribbons}

Ribbons thus produced were characterized to see if they were amorphous and displayed other reported characteristics of such ribbons.

\subsection{Characterization systems}

A Carl-Zeiss MP-320 shadowgraph was used to measure the ribbon width. It has an optical projector with a magnification of $100 \times$ and a cross wire attached to a micrometer screw gauge. Ribbon thickness was measured using a micrometer screw gauge. Rectangular cross section was assumed. Surface profile was obtained with a Rank Taylor Hobson Talysurf 10 equipped with a diamond point sensor whose vertical movement as it traverses the specimen, is recorded.

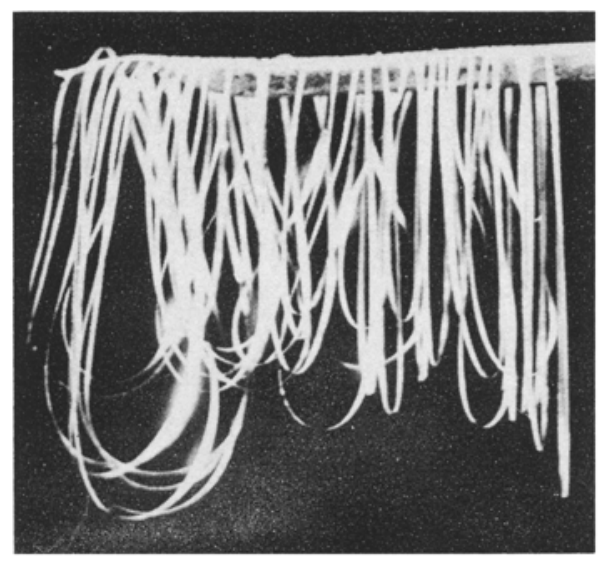

Figure 3. Photograph of an $8 \mathrm{~m}$ long continuous ribbon produced in the laboratory. 
Transmission electron micrographs and selected area diffraction patterns were recorded using a Philips EM 301 transmission electron microscope operated at $100 \mathrm{kV}$. Samples were thinned in a Struers electrolytic jet thinner.

Tensile tests were performed on an Instron TT-CM-L machine with a $100 \mathrm{~kg}$ load cell. Microhardness was measured on a Tukon tester at $0.5 \mathrm{~kg}$ load.

Fracture surfaces of the tensile tested specimens were observed on an ISI 60 scanning electron microscope at $15 \mathrm{kV}$ acceleration and with tilt angle varying between -5 and $30^{\circ}$.

\subsection{Electron micrograph and diffraction pattern}

A transmission electron micrograph and the corresponding selected area diffraction pattern of a ribbon are given in figure 4 . The micrographs and the diffraction patterns from the ribbons of all of other compositions in table 1 were similar. The diffraction pattern shows the typical halo characteristic of amorphous materials and indicates that the glassy state has been achieved. The amorphous nature of the ribbon is further confirmed by the DTA observations reported later. The micrograph is essentially featureless with little or no contrast.

\subsection{Ribbon geometry}

Width, thickness, and surface characteristics of the ribbons have been observed and the results are detailed below.

Table 2 presents the data on the average width and thickness of the ribbons. Although this data is from the alloys of different compositions, it can probably still be grouped together for analysis as the compositions are similar. Such data are usually analyzed in terms of empirical correlations which can also be rationalized from some theoretical considerations (Vincent et al 1981). Here we use the correlation observed by Liebermann (1980) which is applicable when the value of the volumetric flow rate $Q$, is low. (The value of $Q$ is given by W.t.s, where $W$ is the width, $t$ is the thickness of the

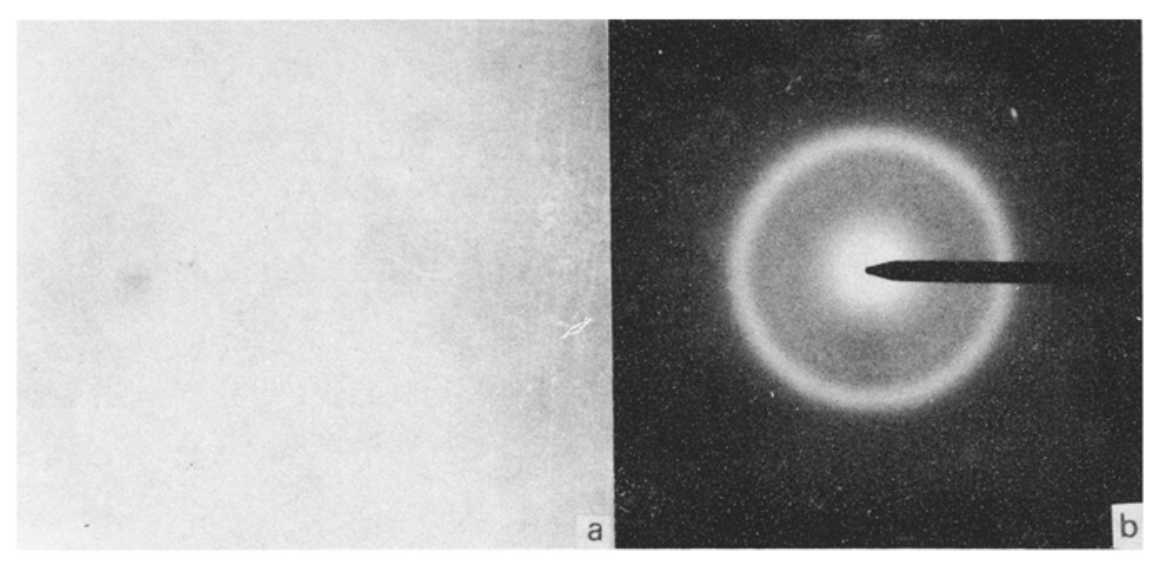

Figure 4. (a) Transmission electron micrograph and (b) the corresponding selected area diffraction pattern from a ribbon. 
Table 2. Average width (w) and thickness ( $t)$ of the ribbons

\begin{tabular}{cccc}
\hline $\begin{array}{c}\text { Alloy } \\
\text { number }\end{array}$ & a/o Boron & $\begin{array}{c}W \\
\mathrm{~mm}\end{array}$ & $\begin{array}{c}t \\
10^{-3} \mathrm{~mm}\end{array}$ \\
\hline 1 & 14.6 & 0.95 & $25 \cdot 1$ \\
2 & 16.7 & 0.60 & $31 \cdot 4$ \\
3 & 17.9 & 0.88 & $34 \cdot 1$ \\
4 & 18.6 & 0.70 & $22 \cdot 7$ \\
5 & 19.9 & 0.70 & $21 \cdot 0$ \\
\hline
\end{tabular}

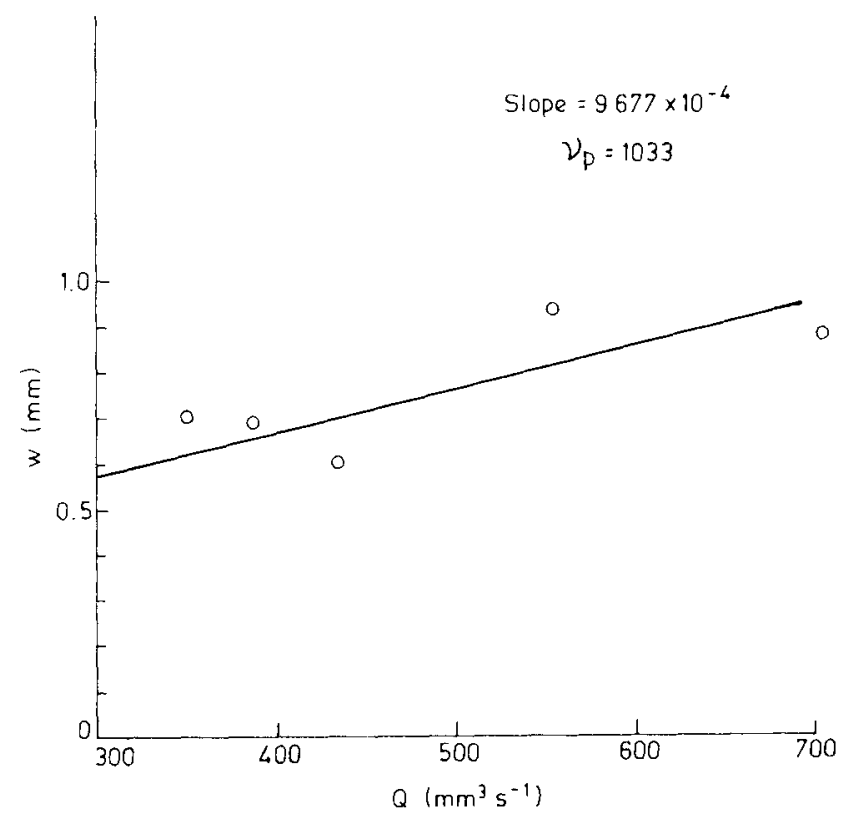

Figure 5. Effect of the volumetric fiow rate on the width of the ribbon.

ribbon, and $s$ is the linear speed of the chill block. In practice, $Q$ is varied by varying the diameter of the nozzle orifice). Liebermann (1980) and Pavuna (1981) have shown that under such conditions the relations between width $W$ and $Q$ is linear. Such a relationship is also found by us (figure 5). The reciprocal of the slope of the $Q$ vs $W$ plot is called dynamic melt puddle viscosity, $v \rho$, as it has the same dimensions as the kinematic viscosity. However, as Agrawal (1982) has shown, this cannot be taken as the average of the viscosities in the solidifying puddle as it is smaller than such an average by a factor of more than 100 . The value of $v \rho$, here is $1033 \mathrm{~mm}^{2} \mathrm{sec}^{-1}$ which is in the range of $950-1200 \mathrm{~mm}^{2} \mathrm{sec}^{-1}$ reported in the literature (Liebermann 1980; Pavuna 1981).

The surface profile across the width of a ribbon is shown in figure 6 and is representative of the profiles obtained for the other ribbon samples also. The trace shows a characteristic, edge-shouldered pattern indicating that the hydraulic jump effect (Olsson and Turkdogan 1966) is operative here. 

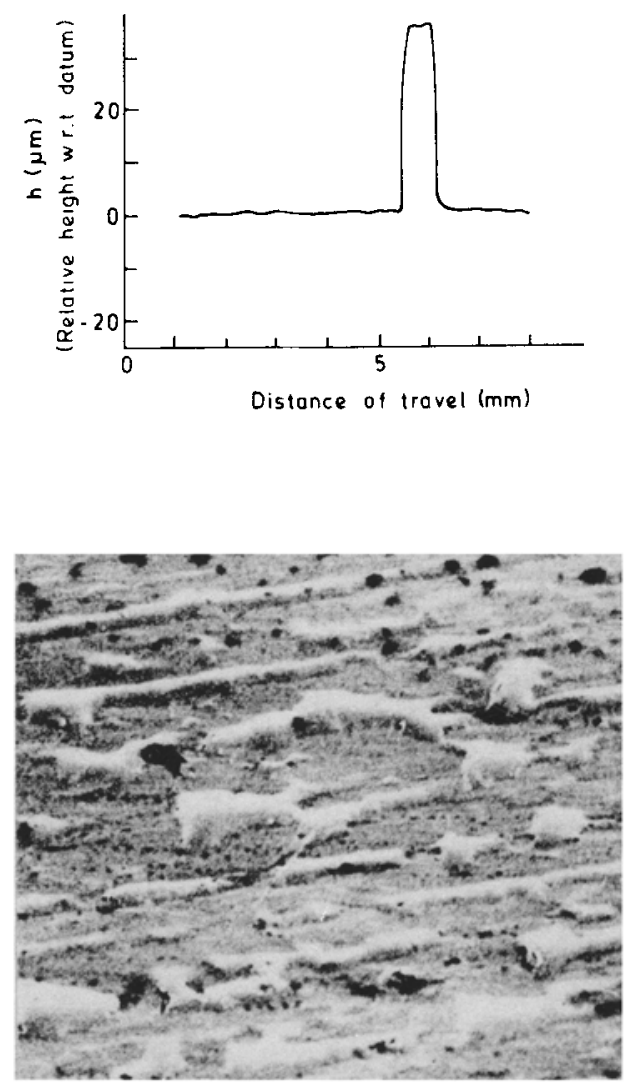

Figure 6. Surface profile across the width of a ribbon.
Figure 7. Scanning electron micrograph of the dull surface of a ribbon.

One surface of the ribbon is bright and shiny and essentially featureless underneath a microscope. The other surface is dull and heavily marked with elongated depressions. An SEM picture of the dull surface of the ribbon is shown in figure 7. The depressions on the ribbon surface are due to expansion and dragging of the air absorbed on the surface of the copper wheel upon contact with the molten alloy (Gyorgy 1978).

\subsection{Mechanical properties}

The strength, modulus and the hardness of the ribbons are given in table 3 . The average value of the tensile strength (e.g. $3.71 \mathrm{GPa}$ for $19.9 \mathrm{a} / \mathrm{oB}$ ) measured on the as-cast specimens compares very well with those reported in literature (3.74 GPa for $\mathrm{Fe}_{80} \mathrm{~B}_{20}, \mathrm{Li}$ 1981). The hardness and the moduli values are somewhat lower.

Fracture surface of a ribbon broken in tension is shown in figure 8. The typical vein pattern and the shear offset regions characteristic of the amorphous ribbons are clearly visible.

\subsection{DTA results}

The $\Delta T$ vs $T$ plots for all the compositions are given in figure 9. These curves can be examined in the light of the known features of the transformation occurring in 
Table 3. Strength, modulus and hardness of the ribbons

\begin{tabular}{|c|c|c|c|c|c|c|c|}
\hline \multirow{3}{*}{ Alloy } & \multicolumn{3}{|c|}{ Ultimate tensil strength } & \multicolumn{3}{|c|}{ Young's modulus } & \multirow{3}{*}{$\frac{\text { Hardness }}{\text { GPa }}$} \\
\hline & \multicolumn{3}{|c|}{ GPa } & \multicolumn{3}{|c|}{ GPa } & \\
\hline & $\begin{array}{l}\text { Maxi- } \\
\text { mum }\end{array}$ & $\begin{array}{l}\text { Mini- } \\
\text { mum }\end{array}$ & Mean & $\begin{array}{l}\text { Maxi- } \\
\text { mum }\end{array}$ & $\begin{array}{l}\text { Mini- } \\
\text { mum }\end{array}$ & Mean & \\
\hline 1 & 2.63 & $2 \cdot 16$ & 2.45 & 98.5 & 93.0 & 96.0 & $7 \cdot 7$ \\
\hline 2 & $2 \cdot 88$ & $2 \cdot 32$ & $2 \cdot 71$ & $105 \cdot 7$ & 98.4 & $102 \cdot 2$ & 8.9 \\
\hline 3 & 3.45 & $3 \cdot 23$ & 3.38 & $107 \cdot 5$ & 104.8 & $105 \cdot 5$ & 9.8 \\
\hline 4 & 3.41 & $3 \cdot 30$ & $3 \cdot 36$ & $107 \cdot 7$ & $104 \cdot 4$ & $106 \cdot 5$ & $9 \cdot 7$ \\
\hline 5 & 3.82 & 3.54 & 3.71 & $135 \cdot 0$ & 121.8 & $126 \cdot 6$ & 10.6 \\
\hline
\end{tabular}

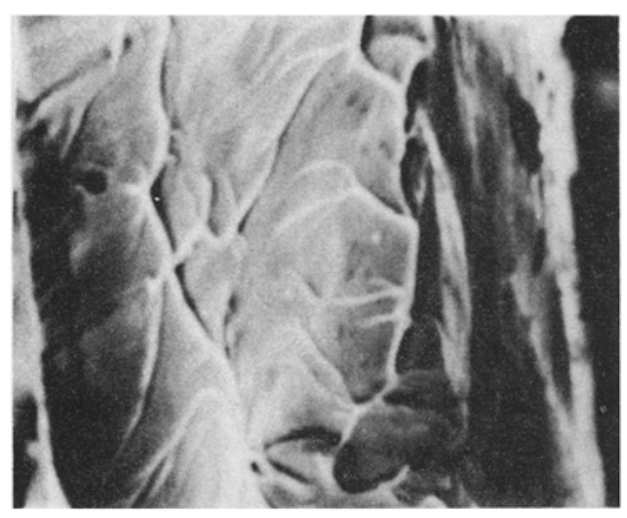

Figure 8. Fracture surface of a ribbon broken in tension.

amorphous iron boron alloys on heating, although some differences can be expected due to the presence of additional elements in the ribbons under study.

Koster and Harold (1981) define three possible methods of crystallization in Fe-B metallic glasses depending on the chemical composition. Primary crystallization occurs in the hypoeutectic composition (less than $17 \mathrm{a} / \mathrm{o}$ boron) and results in precipitation of $\alpha-\mathrm{Fe}$ between 300 and $450^{\circ} \mathrm{C}$. At temperatures higher than $550^{\circ} \mathrm{C}, \mathrm{Fe}_{3} \mathrm{~B}$ starts to crystallize from the boron enriched matrix. At still higher temperatures the $\mathrm{Fe}_{3} \mathrm{~B}$ crystals decompose into $\alpha-\mathrm{Fe}$ and $\mathrm{Fe}_{2} \mathrm{~B}$.

Eutectic crystallization occurs in the range $17-20 \mathrm{a} / \mathrm{o}$ boron. $\alpha-\mathrm{Fe}$ and $\mathrm{Fe}_{3} \mathrm{~B}$ precipitate out simultaneously from the amorphous matrix at about $500^{\circ} \mathrm{C}$. The $\mathrm{Fe}_{3} \mathrm{~B}$ breakdown then occurs as before at a higher temperature.

Polymorphous crystallization occurs in the hypereutectic $\mathrm{Fe}_{75} \mathrm{~B}_{25}$ in which the amorphous phase transforms into a single crystalline phase, $\mathrm{Fe}_{2} \mathrm{~B}$.

The DTA data of Matsuura (1979) conforms to the findings of Koster and Harold (1981). For $\mathrm{B}$ less than $16 \mathrm{a} / \mathrm{o}$, at a heating rate of $1^{\circ} \mathrm{C}$ per minute, two peaks at $400^{\circ} \mathrm{C}$ and $495^{\circ} \mathrm{C}$, corresponding to the precipitation of $\alpha-\mathrm{Fe}$ and $\mathrm{Fe}_{3} \mathrm{~B}$, were observed. For $\mathrm{B} \leqslant 16 \mathrm{a} / \mathrm{o}$ only one peak at $460^{\circ} \mathrm{C}$ due to coprecipitation of $\mathrm{Fe}_{3} \mathrm{~B}$ and $\alpha-\mathrm{Fe}$ was 


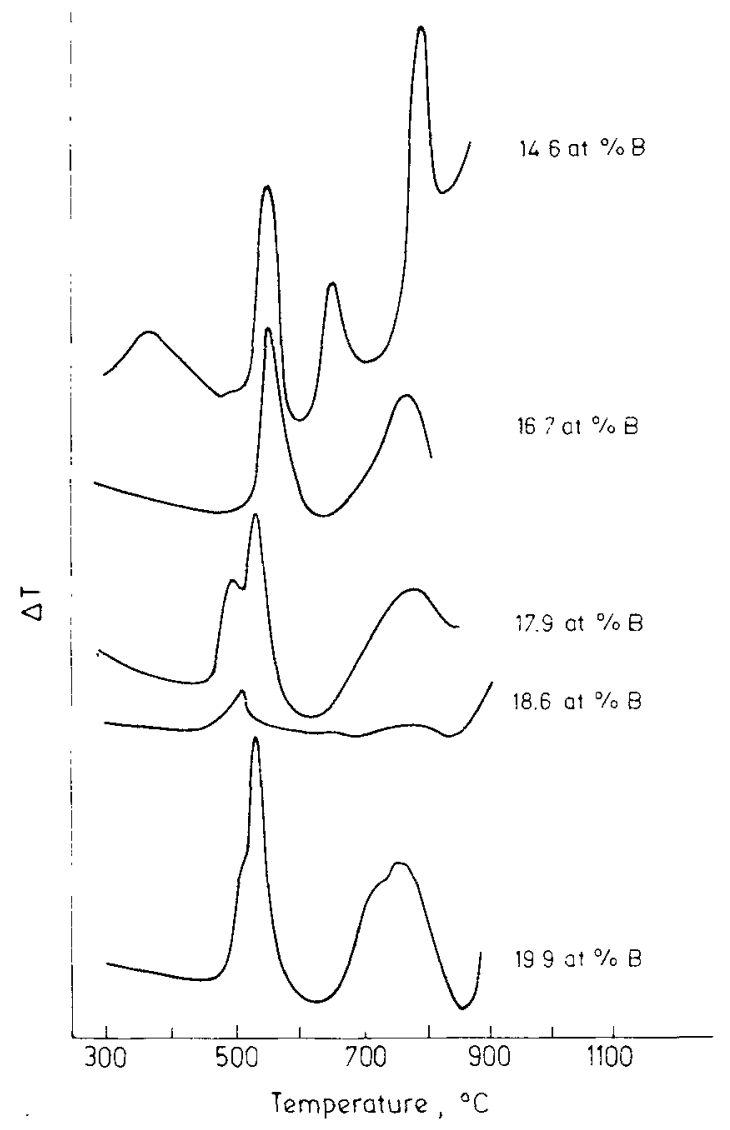

Figure 9. DTA plots for ribbons of compositions indicated in the figure.

observed. The $\mathrm{Fe}_{3} \mathrm{~B}$ peak was found to shift to lower temperature for $\mathrm{B} \leqslant 16 \mathrm{a} / \mathrm{o}$ as compared to that for $B \geqslant 16 \mathrm{a} / 0$.

Inal et al (1981) observed sharp changes in resistivity of $\mathrm{Fe}_{80} \mathrm{~B}_{20}$ at $395,500,720$ and $840^{\circ} \mathrm{C}$ during continuous heating. They then performed annealing treatments at these temperatures. The interesting feature of their results is the formation of a $\mathrm{Fe}_{23} \mathrm{~B}_{6}$ phase at $720^{\circ} \mathrm{C}$ which is directly obtained from the amorphous $\mathrm{Fe}_{80} \mathrm{~B}_{20}$ and not as a secondary product.

Despite the presence of appreciable amounts of alloying elements other than boron and iron in our alloys, our results follow the above pattern quite closely. The peak below $400^{\circ} \mathrm{C}$ ( $\alpha-\mathrm{Fe}$ primary crystallization) is found only in the $14.6 \mathrm{a} / \mathrm{o}$ boron alloy. The $\mathrm{Fe}_{3} \mathrm{~B}$ peak shifts to lower temperatures for $\mathrm{B} \geqslant 16 \mathrm{a} / \mathrm{o}$ (the higher peak temperatures are probably due to the higher heating rates, $10^{\circ} \mathrm{C} \mathrm{min}{ }^{-1}$, in our experiments). The peak at $720^{\circ} \mathrm{C}$ occurs only for the composition closest to $\mathrm{Fe}_{80} \mathrm{~B}_{20}$ and this peak can be attributed to the formation of $\mathrm{Fe}_{23} \mathrm{~B}_{6}$ reported by Inal et al (1981). In fact, our results support the view that the transformation is a direct one and not one via an intermediate product. 


\section{Acknowledgement}

This work has been supported by a grant from the Board of Research in Nuclear Science, Department of Atomic Energy, Government of India.

\section{References}

Agrawal D C 1982 J. Mater. Sci. Lett. 1385

Bhanu Prasad B, Bhatnagar Anil K, Venkataram S and Chandrasekharaiah M N 1984 Bull. Mater. Sci. 621 Budhani R C, Goel T C and Chopra K L 1982 Bull. Mater. Sci. 5549

Chakachery E A and Agrawal D C 1982 36th Annual Technical Meeting, Indian Institute of Metals, Rourkela, November

Gyorky E M 1978 in Metallic glasses (eds.) J J Gilman and H J Leamy (Metals Park, Ohio: American Society for Metals) p. 286

Inal O T, Robino C V, Keller L, Yost F G and Kornowesky M M 1981 J. Mater. Sci. 163183

Koster H and Harold H 1981 in Glassy metals (eds.) H J Guntheroldt and H Bock (Berlin: Springer Verlag)

Li J C M 1981 Treatise on materials science and technology (New York: Academic Press) p. 20

Liebermann H H 1980 Mater. Sci. Eng. 43203

Luborsky F E, Reeve J, Davies H A and Liebermann H H 1982 IEEE Trans. Magn. 18 B85

Matsuura M 1979 Solid State Commun. 30231

Namboodhiri T K G, Ramesh T A, Singh G and Sehgal H 1983 Mater. Sci. Eng. 6123

Olsson R G and Turkdogan E T 1966 Nature 211813

Parashar R S, Sunandana C S and Bhatnagar A K 1984 Bull. Mater. Sci. 61

Pavuna D 1981 J. Mater. Sci. 162419

Sridhar R and Agrawal D C 1983 Proceedings: Symposium on amorphous materials, BARC, Bombay, October $5-7,295$

Srinath L S 1983 Advanced mechanics of solids (New Delhi: Tata McGraw Hill) p. 283

Tenwick M J and Davies H A 1984 Mater. Sci. Eng. 63 L1

Vincent J H, Herbertson J G and Davies H A 1981 Proc. fourth international conference on rapidly quenched metals (Sendai, Japan) August 24-28 Vol. 1, p. 77

Yousuf M and Govinda Rajan K 1984 J. Mater. Sci., Lett. 3149 